\title{
Sn-modified Ni-nanowire array films prepared by electrodeposition and their electrochemical properties as an anode material of lithium-ion batteries
}

\author{
Takeo Hyodo, Masayoshi Kanno, Toru Kaijima, Takeshi Ohgai and Yasuhiro Shimizu \\ Graduate School of Engineering \\ Nagasaki University \\ 1-14 Bunkyo-machi, Nagasaki 852-8521, Japan \\ hyodo@nagasaki-u.ac.jp
}

\begin{abstract}
Ni-nanowire array films were prepared by general galvanostatic electrodeposition employing a polycarbonate membrane filter (pore diameter: $0.1 \mu \mathrm{m}$ or $0.8 \mu \mathrm{m}$ ) as a template and subsequent dissolution of the membrane filter in chloroform. Thereafter the Ni-nanowire array films were modified with Sn by pulsed electrodeposition. Morphology of Sn-modified Ninanowire array films obtained was largely dependent on the microstructure of the membrane filter and the conditions of pulsed electrodeposition of $\mathrm{Sn}$. It was confirmed that uniform deposition of $\mathrm{Sn}$ right into the Ni-nanowire array structure improved charge-discharge characteristics of the Sn-modified Ninanowire array films as an anode of lithium-ion batteries.
\end{abstract}

Keywords; tin; nickel; nanowire; anode; lithium-ion battery; electrodeposition

\section{INTRODUCTION}

Lithium-ion batteries are generally utilized as a rechargeable electric source in different portable application fields such as mobile phones and laptop computers, because the electrode materials (graphite as an anode and lithium cobaltite as a cathode) show highly-efficient lithium-insertion/ deinsertion properties. However, the capacity of the conventional lithium-ion batteries is insufficient as an electric source for large-scale application such as electric vehicles. Recently, metallic Sn metal as well as Sn-based materials (e.g., $\mathrm{SnO}_{2}, \mathrm{SnO}$ and Sn-based alloy) are very noteworthy as a potential anode material of lithium-ion batteries, because their theoretical capacities are large (994 $\mathrm{mAh} \mathrm{g}^{-1}$ for the metallic $\mathrm{Sn})$ in comparison with that of graphite (372 $\left.\mathrm{mAh} \mathrm{g}^{-1}\right)$. However, their large expansion and shrinkage of volume associated with charge and discharge process (i.e., alloying and de-alloying of Sn with lithium) markedly reduce the chargedischarge cyclic performance of the Sn-based anode. Therefore, numerous efforts have been directed to improving the charge-discharge cyclic performance by controlling their compositions and microstructure [1-12].

We also have already reported some potential Sn-based anode materials. Mesoporous (m-) $\mathrm{SnO}_{2}$ powder with high specific surface area (over $200 \mathrm{~m}^{2} \mathrm{~g}^{-1}$ ) and small crystallite size (ca. $2 \mathrm{~nm}$ ) was employed as a starting material and then the use of the Sn-based anode material fabricated by reducing the $\mathrm{m}$ $\mathrm{SnO}_{2}$ powder in argon and subsequently in hydrogen at elevated temperatures largely enhanced the charge-discharge cyclic performance [13]. Introduction of a macroporous cobalt or nickel film between an electrodeposited Sn film and a copper substrate (current collector) by electrodeposition utilizing polymethylmethacrylate as a template was also quite effective in improving the charge-discharge cyclic performance [14]. Based on these previous results, Sn has been electrochemically modified on Ni-nanowire array films fabricated by electrodeposition employing a polycarbonate membrane filter as a template, and charge-discharge characteristics of the obtained Sn-modified Ni-nanowire array films as an anode of lithium-ion batteries have been investigated in this study.

\section{EXPERIMENTAL}

\section{A. Preparation of nickel-nanowire array films}

After $\mathrm{Au}$ was deposited on one side of a polycarbonate membrane filter (MF- $n, n$ (pore diameter shown in the catalog): $0.1 \mu \mathrm{m}$ or $0.8 \mu \mathrm{m}$, Advantec Toyo Ltd.) by ion sputtering, it was attached on a $\mathrm{Cu}$ foil (diameter: $2 \mathrm{~cm}$, thickness: $20 \mu \mathrm{m}$ ) by double-faced adhesive conductive tape. $\mathrm{Ni}$ was electrodeposited in the pores of the MF- $n$ filter in the electrolytic aqueous solution containing $\mathrm{NiSO}_{4} \cdot 6 \mathrm{H}_{2} \mathrm{O}(120 \mathrm{~g}$ $\left.\mathrm{dm}^{-3}\right)$ and $\mathrm{H}_{3} \mathrm{BO}_{4}\left(45 \mathrm{~g} \mathrm{dm}^{-3}\right)$ at a voltage of $-1.0 \mathrm{~V}$ at $40^{\circ} \mathrm{C}$ for an appropriate electrolytic period [15]. After the MF- $n$ filter was dissolved in chloroform, a Ni-nanowire array (Ni-n) film was obtained. A conventional $\mathrm{Ni}$ film on $\mathrm{Cu}$ foil (Ni-c) was also fabricated by electrodeposition in the same solution, as a reference.

\section{B. Electrodeposition of Sn on nickel-nanowire array films}

$\mathrm{Ni}-n$ films were immersed in the electrolytic aqueous solution containing $\mathrm{SnSO}_{4} \cdot 6 \mathrm{H}_{2} \mathrm{O}\left(50 \mathrm{~g} \mathrm{dm}^{-3}\right)$, o-cresolsulfonic acid $\left(50 \mathrm{~g} \mathrm{dm}^{-3}\right), \beta$-naphthol $\left(1 \mathrm{~g} \mathrm{dm}^{-3}\right)$, gelatin $\left(1 \mathrm{~g} \mathrm{dm}^{-3}\right)$ and $\mathrm{H}_{2} \mathrm{SO}_{4}\left(90 \mathrm{~g} \mathrm{dm}^{-3}\right)$, and $\mathrm{Sn}$ was deposited on the $\mathrm{Ni}-n$ films by pulsed electrodeposition (condition $\mathrm{P}(\mathrm{a}): 6.5 \mathrm{~mA} \mathrm{~cm}^{-2}$ for $30 \mathrm{~s}$ and $32.5 \mathrm{~mA} \mathrm{~cm}^{-2}$ for $0.1 \mathrm{~s}, 10$ times, condition $\mathrm{P}(\mathrm{b}): 6.5 \mathrm{~mA}$ 
$\mathrm{cm}^{-2}$ for $30 \mathrm{~s}$ and $65.0 \mathrm{~mA} \mathrm{~cm}{ }^{-2}$ for $0.1 \mathrm{~s}, 10$ times). The Snmodified Ni-nanowire array films obtained were denoted as Sn-M/Ni-n (M (electrodeposition condition): P(a) or P(b)). Sn was deposited by galvanostatic electrodeposition (condition $\mathrm{G}$ : $6.5 \mathrm{~mA} \mathrm{~cm}^{-2}$ for $300 \mathrm{~s}$ ) also on the reference Ni-c film. The reference composite film was denoted as $\mathrm{Sn}-\mathrm{G} / \mathrm{Ni}-\mathrm{c}$. All samples obtained were heat-treated at $240^{\circ} \mathrm{C}$ for $12 \mathrm{~h}$ under vacuum condition controlled by a general rotary pump. Morphology of all samples was observed by scanning electron microscopy (SEM, JEOL, JCM-5700).

\section{Fabrication of test cell and its charge-discharge} characteristics

An exploded schematic drawing of a hand-made test cell is shown in Fig. 1. First, a mixed solution of ethylene carbonate (EC) and dimethyl carbonate (DMC) (EC : DMC = $1: 2$ in mass ratio) containing $1 \mathrm{M} \mathrm{LiPF_{6 }}$ as an electrolyte was immersed in both a glass filter (Advantec Toyo Ltd.; GA-100) and a separator (Celgard, LLC; 2400). Then they were sandwiched between the Sn-M/Ni-n or the Sn-G/Ni-c film on the $\mathrm{Cu}$ foil as a working electrode and a $\mathrm{Li}$ foil with a stainless mesh as a counter electrode. Thereafter they were set in a hand-made test cell in an argon-filled glove box. Chargedischarge characteristics of the test cells obtained were galvanostatically measured in the cell voltage range of $0.02 \sim 1.50 \mathrm{~V}$ (vs. $\mathrm{Li} / \mathrm{Li}^{+}$) at a current density of $0.02 \mathrm{~mA} \mathrm{~cm}{ }^{-2}$ by a typical battery test system (Toyo System Co., Ltd., TOSCAT-3100H).

\section{RESULTS AND DISCUSSION}

A. Morphology of polycarbonate membrane filters, nickelnanowire array films and tin-modified nickel-nanowire array films

Figures 2 and 3 show SEM photographs of MF-n filters and

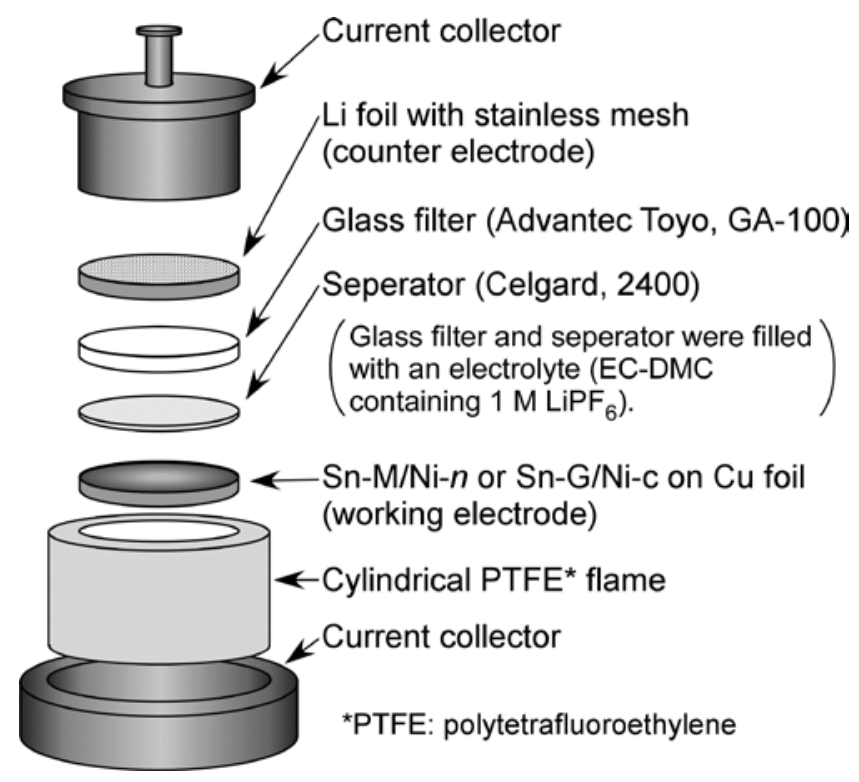

Figure 1. An exploded schematic drawing of a hand-made test cell.

$\mathrm{Ni}-n$ films. The number density of nanowires of Ni-0.1 film prepared, ca. $4.5 \times 10^{8} \mathrm{~cm}^{-2}$, was almost similar to that of pores on the surface of the MF-0.1 filter, ca. $5.7 \times 10^{8} \mathrm{~cm}^{-2}$, and the size of nanowires of the $\mathrm{Ni}-0.1$ film was ca. $0.11 \mu \mathrm{m}$ in diameter and ca. $3.3 \mu \mathrm{m}$ in length. As for the Ni-0.8 film, the number density of nanowires, ca. $3.1 \times 10^{7} \mathrm{~cm}^{-2}$, was also almost equal to that of pores on the surface of the MF-0.8 filter, ca. $2.5 \times 10^{7} \mathrm{~cm}^{-2}$, and the size of nanowires of the Ni-0.8 film was ca. $0.95 \mu \mathrm{m}$ in diameter and ca. $3.2 \mu \mathrm{m}$ in length. The aspect ratio of the nanowires of the Ni-0.1 film (ca. 30) was much larger than that of the Ni-0.8 film (ca. 3.4). In addition, the nanowires of the $\mathrm{Ni}-0.1$ film were relatively dense, whereas the morphology of edge parts of the nanowires of the Ni-0.8 film was nanotube-like structure. This is probably because a small amount of gold was deposited also on the inside wall of relatively-large pores of the MF-0.8 filter when it was deposited on one side of the MF-0.8 filter by ion sputtering (pre-treatment process before the $\mathrm{Ni}$ electrodeposition) and

(a) MF-0.1

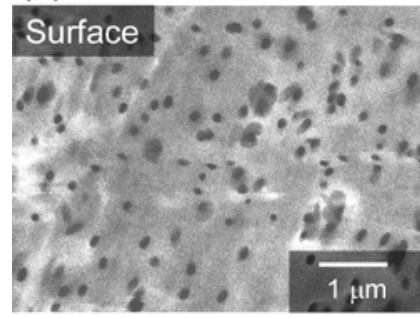

(b) Ni-0.1

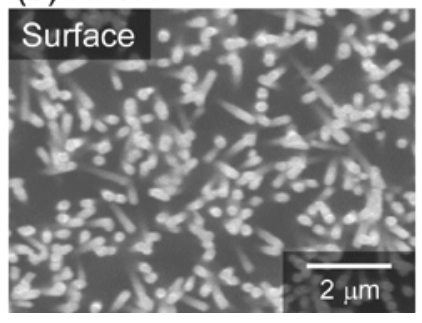

Figure 2. SEM photographs of an MF-0.1 filter and a Ni-0.1 film.

(a) MF-0.8
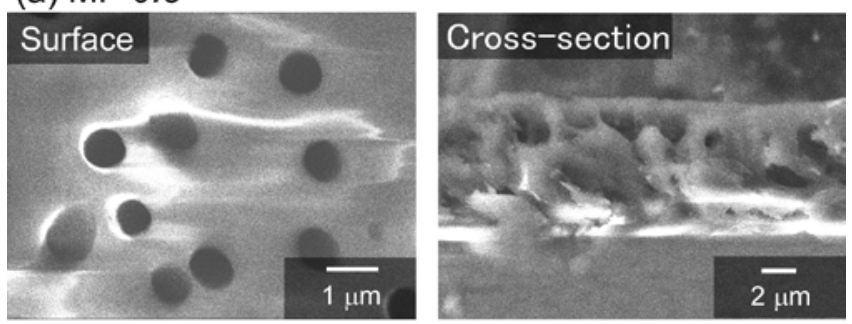

(b) Ni-0.8
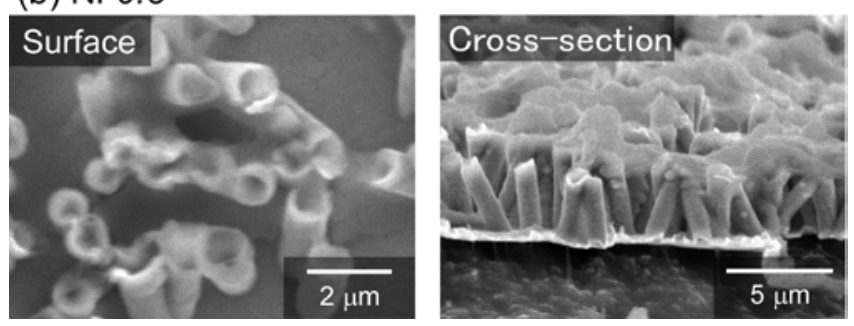

Figure 3. SEM photographs of an MF-0.8 filter and a Ni-0.8 film.
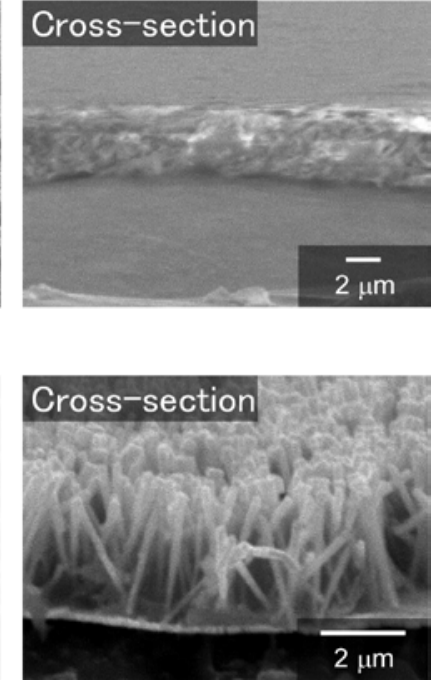
. 
(a) $\mathrm{Sn}-\mathrm{P}(\mathrm{a}) / \mathrm{Ni}-0.1$
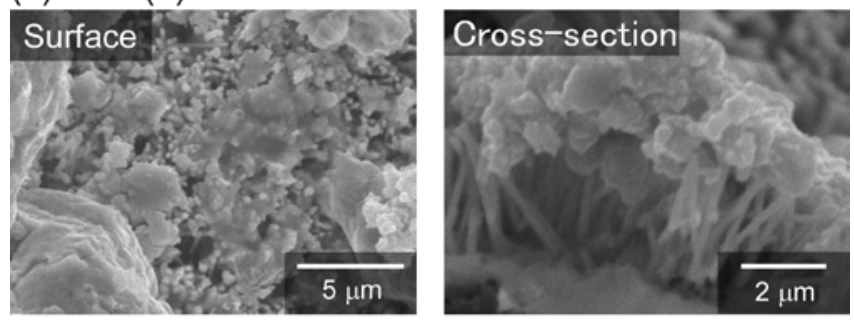

(b) $\mathrm{Sn}-\mathrm{P}(\mathrm{b}) / \mathrm{Ni}-0.1$
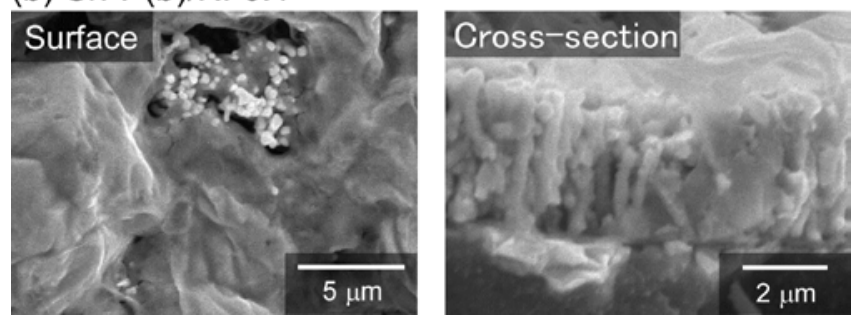

Figure 4. SEM photographs of Sn-M/Ni-0.1 films.

(a) $\mathrm{Sn}-\mathrm{P}(\mathrm{a}) / \mathrm{Ni}-0.8$
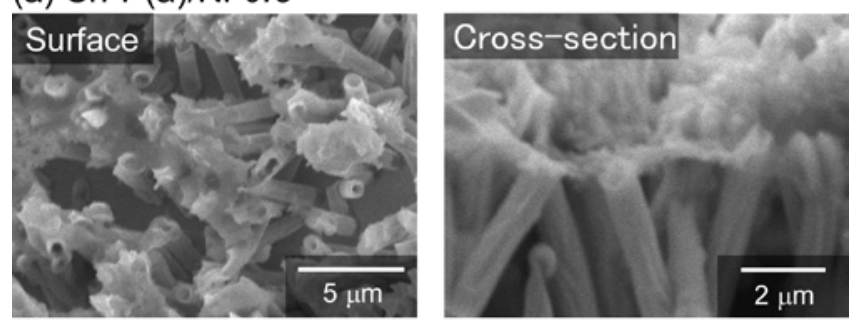

(b) $\mathrm{Sn}-\mathrm{P}(\mathrm{b}) / \mathrm{Ni}-0.8$
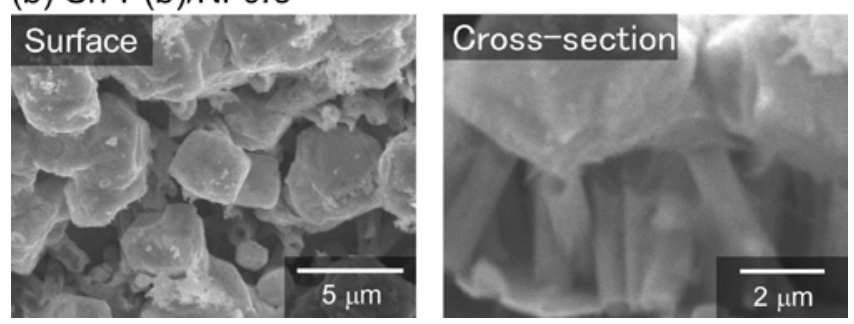

Figure 5. SEM photographs of Sn-M/Ni-0.8 films.

thus Ni was easily electrodeposited along the gold-coated inner wall. These results show that $\mathrm{Ni}$ was effectively electrodeposited into the almost all pores of the MF- $n$ filters.

Figure 4 shows SEM photographs of Sn-M/Ni-0.1 films. The amount of $\mathrm{Sn}$ deposited in the $\mathrm{Sn}-\mathrm{P}(\mathrm{b}) / \mathrm{Ni}-0.1$ film was apparently larger than that in the $\mathrm{Sn}-\mathrm{P}(\mathrm{a}) / \mathrm{Ni}-0.1 \mathrm{film}$, because the amount of electric charge transferred under the period of electrodeposition for the $\mathrm{Sn}-\mathrm{P}(\mathrm{b}) / \mathrm{Ni}-0.1$ film was larger than that for the Sn-P(a)/Ni-0.1 film. In addition, Sn in the Sn$\mathrm{P}(\mathrm{b}) / \mathrm{Ni}-0.1$ film was uniformly deposited right into the nanowire array structure of the Ni-0.1 film, while a little amount of $\mathrm{Sn}$ in the Sn-P(a)/Ni-0.1 film was partially deposited among the nanowires of the $\mathrm{Ni}-0.1$ film and its majority was found near the top of the Ni-0.1 film. The behavior implies a large effect of the current density during the pulsed electrodeposition on the morphology of Sn deposited, but the

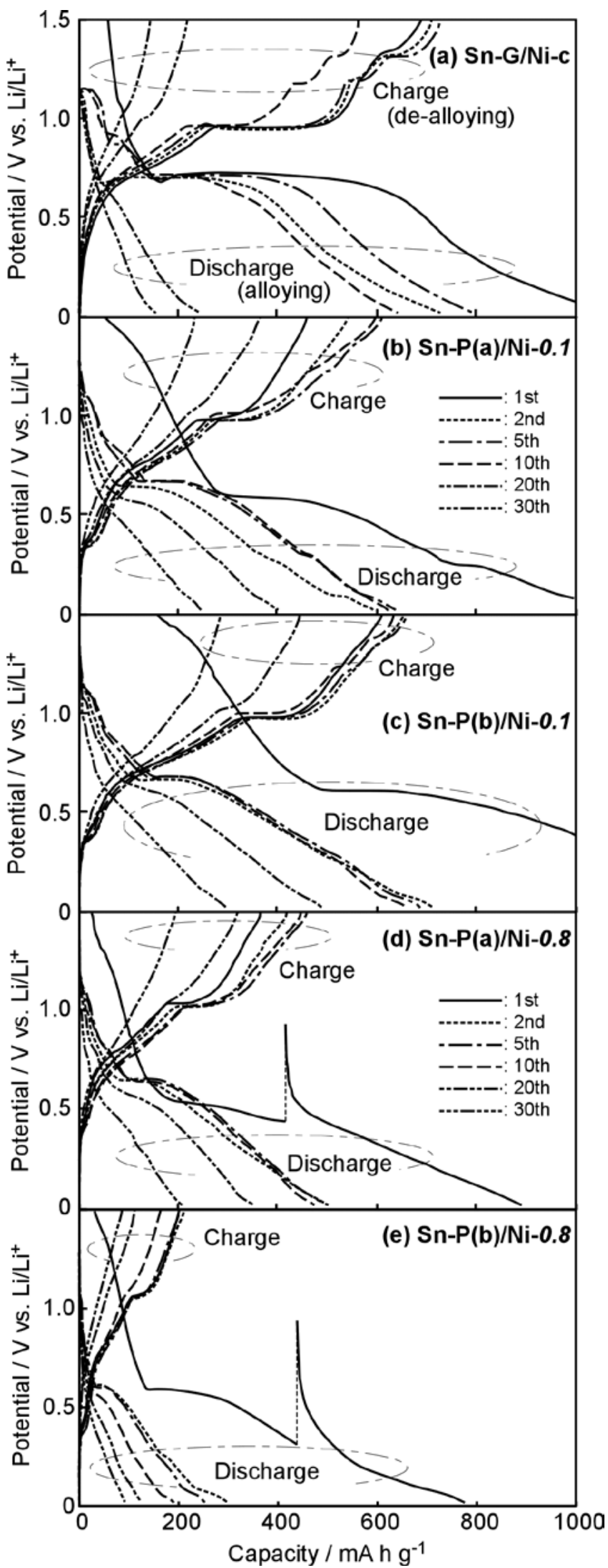

Figure 6. Representative chronopotentiograms of test cells fabricated with $\mathrm{Sn}-\mathrm{M} / \mathrm{Ni}-n$ films and a Sn-G/Ni-c film in the cell voltage range of $0.02 \sim 1.50$ $\mathrm{V}\left(\mathrm{vs} . \mathrm{Li} / \mathrm{Li}^{+}\right.$) at a current density of $0.02 \mathrm{~mA} \mathrm{~cm}{ }^{-2}$. 
(a) Discharge cyclic performance

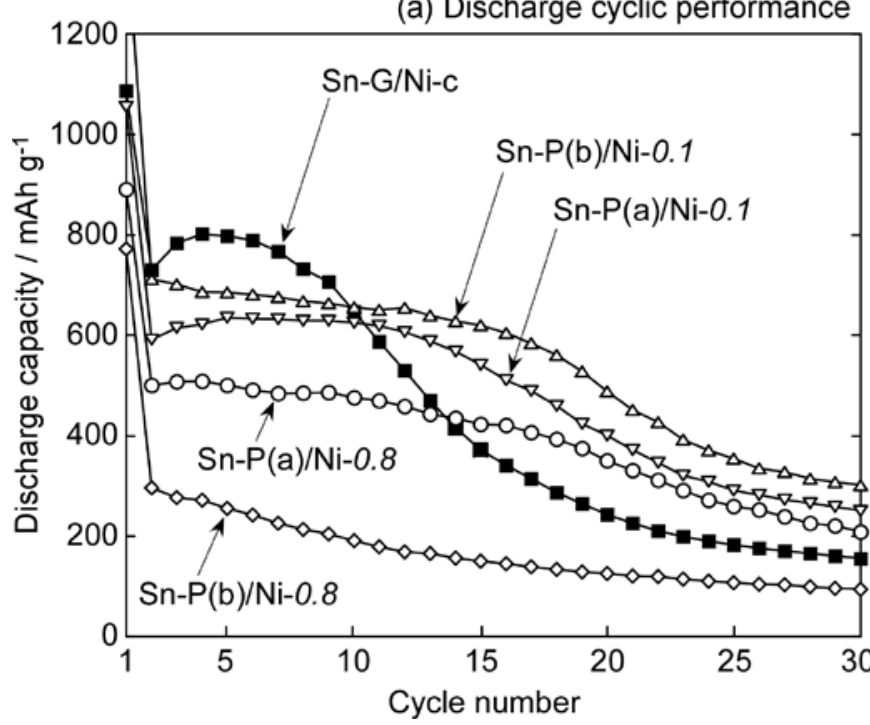

(b) Charge cyclic performance

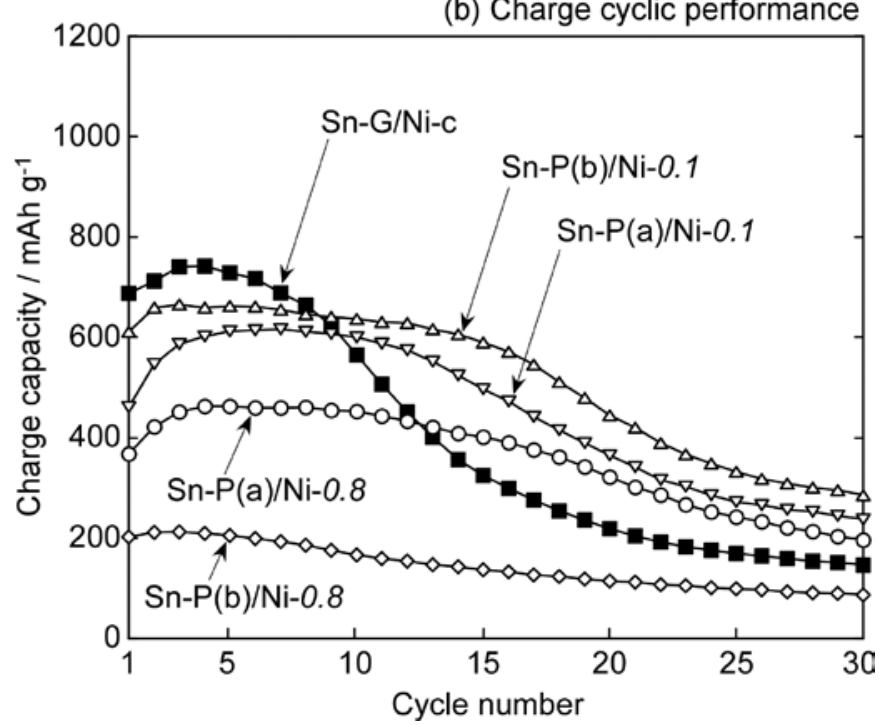

Figure 7. Charge and discharge cyclic performances of test cells fabricated with Sn-M/Ni- $n$ films and a Sn-G/Ni-c film.

exact reason for this phenomenon is not clear at present. For the Sn-M/Ni-0.8 film, on the other hand, Sn was only deposited on the top of nanowires of the Ni-0.8 film and it was hardly found inside the nanowire array structure. Generally, metal was easily electrodeposited at the edge and the protruding surface of electrodes. As the number of Ni nanowires of the $\mathrm{Sn}-\mathrm{M} / \mathrm{Ni}-0.8$ film was much smaller than that of the $\mathrm{Sn}-\mathrm{M} / \mathrm{Ni}-$ 0.1 film, electric fields easily concentrated on the top of $\mathrm{Ni}$ nanowires of the $\mathrm{Sn}-\mathrm{M} / \mathrm{Ni}-0.8$ film in comparison with that of the $\mathrm{Sn}-\mathrm{M} / \mathrm{Ni}-0.1$ film and thus the Sn bulk might be deposited only at the surface of the Ni-0.8 film.

\section{B. Charge-discharge characteristics of test cells}

Figure 6 shows representative chronopotentiograms of all test cells fabricated with Sn-M/Ni-n films and a Sn-G/Ni-c film in the cell voltage range of $0.02 \sim 1.50 \mathrm{~V}\left(\mathrm{vs} . \mathrm{Li} / \mathrm{Li}^{+}\right.$) at a current density of $0.02 \mathrm{~mA} \mathrm{~cm}^{-2}$. Figure 7 shows charge and discharge cyclic performances of all test cells fabricated with Sn-M/Ni- $n$ films and a Sn-G/Ni-c film, which were obtained from the results of their chronopotentiograms (Fig. 6). Hereafter, test cells fabricated with the $\mathrm{Sn}-\mathrm{M} / \mathrm{Ni}-n$ film and the $\mathrm{Sn}-\mathrm{G} / \mathrm{Ni}-\mathrm{C}$ film are referred to as $\mathrm{Sn}-\mathrm{M} / \mathrm{Ni}-n$ and $\mathrm{Sn}-\mathrm{G} / \mathrm{Ni}-\mathrm{C}$ cells, respectively. Alloying and de-alloying of $\mathrm{Sn}$ with $\mathrm{Li}$ proceeded in charge and discharge processes, respectively. The steep potential change at the capacity of ca. 420 and 440 mAh $\mathrm{g}^{-1}$ of the $\mathrm{Sn}-\mathrm{P}(\mathrm{a}) / \mathrm{Ni}-0.8$ and the $\mathrm{Sn}-\mathrm{P}(\mathrm{b}) / \mathrm{Ni}-0.8$ cells in Figs. 6 (c) and (d), respectively, was anticipated to arise from temporal current interruption. Most potential-capacity curves of all test cells in Fig. 6 exhibited three potential plateaus in the range of $1.1 \sim 1.2 \mathrm{~V}$, ca. $0.8 \sim 0.9 \mathrm{~V}$ and $0.6 \sim 0.7 \mathrm{~V}$ in the discharge (alloying process of $\mathrm{Sn}$ with $\mathrm{Li}$ ), which may be ascribed to the reaction expressed by equations (1) (3), respectively $[1,16,17]$.

$$
\begin{aligned}
& 5 \mathrm{Sn}+2 \mathrm{Li} \rightarrow \mathrm{Li}_{2} \mathrm{Sn}_{5} \\
& \mathrm{Li}_{2} \mathrm{Sn}_{5}+3 \mathrm{Li} \rightarrow 5 \mathrm{LiSn} \\
& 3 \mathrm{LiSn}+4 \mathrm{Li} \rightarrow \mathrm{Li}_{7} \mathrm{Sn}_{3}
\end{aligned}
$$

In addition, a continuous decrease in the potential less than 0.6 $\mathrm{V}$ means further alloying of $\mathrm{Li}_{7} \mathrm{Sn}_{3}$ with $\mathrm{Li}$ (i.e., from $\mathrm{Li}_{7} \mathrm{Sn}_{3}$ to $\mathrm{Li}_{5} \mathrm{Sn}_{2}, \mathrm{Li}_{13} \mathrm{Sn}_{5}, \mathrm{Li}_{7} \mathrm{Sn}_{2}$ and lastly $\left.\mathrm{Li}_{22} \mathrm{Sn}_{5}\right)[1,16,17]$. The Sn$\mathrm{G} / \mathrm{Ni}-\mathrm{C}$ cell showed relatively large charge and discharge capacities of over $700 \mathrm{mAh} \mathrm{g}^{-1}$ until 10th cycle (charge) and 6th cycle (discharge). The capacities reduced drastically after 11th cycle (discharge) and 7th cycle (charge), probably owing to the large volume change in Sn. The capacity of the Sn$\mathrm{M} / \mathrm{Ni}-0.8$ cell was much smaller than that of the $\mathrm{Sn}-\mathrm{G} / \mathrm{Ni}-\mathrm{c}$ cell even in the early cycles (ca. $500 \mathrm{mAh} \mathrm{g}^{-1}$ for the $\mathrm{Sn}-\mathrm{P}(\mathrm{a}) / \mathrm{Ni}-0.8$ cell and less than $300 \mathrm{mAh} \mathrm{g}^{-1}$ for the $\mathrm{Sn}-\mathrm{P}(\mathrm{b}) / \mathrm{Ni}-0.8$ cell as a discharge capacity), probably because the brittle contact between Sn and the Ni-0.8 film (see Fig. 5) might collapse after the first lithium alloying and de-alloying processes. On the other hand, the Sn-M/Ni-0.1 cell maintained relatively large charge and discharge capacities $\left(>600 \mathrm{mAh} \mathrm{g}^{-1}\right)$ in the early cycles and the value of capacity was larger than that of the SnG/Ni-c cell after 11th cycle (discharge) and 10th cycle (charge). Especially, the Sn-P(b)/Ni-0.1 cell showed the largest capacity among all the cells tested. As the well-developed composite structure between $\mathrm{Sn}$ and Ni-nanowire array is formed for the Sn-P(b)/Ni-0.1 film (see Fig. 4), the Ni nanowire array may maintain the sufficient conductivity in the Sn-P(b)/Ni-0.1 film even after continuous lithium alloying and de-alloying with Sn.

\section{CONCLUSION}

After Ni was galvanostatically electrodeposited on the welldeveloped pores of MF- $n$ filters and subsequently the filters was dissolved in chloroform, a Ni- $n$ film was obtained in this study. The morphology of nanowires of the Ni- $n$ films almost reflected that of pores of the MF-n filters. The morphology of Sn deposited in the Ni-n films by pulsed electrodeposition was dependent on the microstructure of the membrane filter (i.e., the number density and diameter of $\mathrm{Ni}$ nanowires prepared) and the conditions of the pulsed electrodeposition. Among all $\mathrm{Sn}-\mathrm{M} / \mathrm{Ni}-n$ cells tested, the $\mathrm{Sn}-\mathrm{P}(\mathrm{b}) / \mathrm{Ni}-0.1$ cell showed the most excellent charge-discharge characteristics as an anode material of lithium-ion batteries. 


\section{REFERENCES}

[1] M. Winter and J. O. Besenhard, "Electrochmemical lithiation of tin and tin-based intermetallics and composites”, Electrochim. Acta, vol. 45, pp. 31-50, 1999.

[2] J. Morales and L. Sánchez, "Electrochemical behavior of $\mathrm{SnO}_{2}$ doped with boron and indium in anodes ofr lithium secondary batteries", vol. 126, pp. 219-226, 1999.

[3] D. J. Kepler, J. T. Vaughey, and M. M. Thackeray, “Copper-tin anodes for rechargeable lithium batteries: an example of the matric effect in an intermetallic system”, J. Power Sources, vol. 81-82, pp. 383-387, 1999.

[4] J. Y. Lee, Y. Xiao, and Z. Liu, “Amorphous $\mathrm{Sn}_{2} \mathrm{P}_{2} \mathrm{O}_{7}, \mathrm{Sn}_{2} \mathrm{~B}_{2} \mathrm{O}_{5}$ and $\mathrm{Sn}_{2} \mathrm{BPO}_{6}$ anodes ofr lithium ion batteries”, Solid State Ionics, vol. 133, pp. 25-35, 2000.

[5] J. Zhu, Z. Lu, S. T. Aruna, D. Aurbach, and A. Gedanken, "Sonochemical synthesis of $\mathrm{SnO}_{2}$ nanoparticles and their prelinminary study as Li insertion electrodes”, Chem. Mater., vol. 12, pp. 2557-2566, 2000.

[6] K. Nishikawa, K. Dokko, K. Kinoshita, S.-W. Woo, and K. Kanamura, "Three-dimensionally ordered macroporous $\mathrm{Ni}-\mathrm{Sn}$ anode for lithium batteries”, J. Power Sources, vol. 189, pp. 726-729, 2009.

[7] S.-W. Woo, N. Okada, M. Kotobuki, K. Sasajima, H. Munakata, K. Kajihara, and K. Kanamura, "Highly patterned cylindrical Ni-Sn alloys with 3-dimensionally ordered macroporous structure as anodes for lithium batteries”, Electrochim. Acta, vol. 55, pp. 8030-8035, 2010.

[8] Y. Fujiwara, "Sn deposition onto $\mathrm{Cu}$ and alloy layer growth by a contact immersion process”, Thin Solid Films, vol. 425, pp. 121-126, 2003.

[9] M. Tian, W. Wang, S.-H. Lee, Y.-C. Lee, and R. Yang, "Enhancing NiSn nanowire lithium-ion anode performance by tailoring active/inactive material interfaces”, J. Power Soueces, vol. 196, pp. 10207-10212, 2011.
[10] H.-R. Jun and W.-J. Lee, "Preparation and Characterication of NiSn/carbon nanofibers composite anode for lithium ion battery”, J. Electrochem. Soc., vol. 158, pp. A644-A652, 2011.

[11] C. S. Nimisha, G. Venkatesh, N. Munichandraiah, and G. M. Rao, “The effect of electrochemical lithiation on physicohemical properties of rfsputtered Sn thin films”, J. Appl. Electrochem., vol. 41, pp. 1287-1294, 2011.

[12] M.-Y. Li, Y. Wang, C.-L. Liu, C. Zhang, and W.-S. Dong, "Synthesis of carbon/tin composite anode materials for lithium-ion batteries”, J. Electrochem. Soc., vol. 159, pp. A91-A97, 2012.

[13] T. Hyodo, S. Koyama, Y. Shimizu, and M. Egashira, "Development of tin oxide-based materials as an anode for secondary lithium-ion batteries”, Reports of the Faculty of Engineering, Nagasaki Univ., vol. 36, pp. 58-63, 2006.

[14] T. Hyodo, H. Ezaki, Y. Shimizu, and M. Egashira, "Sn-based anodematerials with macroporous metal films for secondary lithium-ion batteries”, Reports of the Faculty of Engineering, Nagasaki Univ., vol. 39, pp. 8-14, 2009.

[15] T. Ohgai, R. Washio, and Y. Tanaka, “Anisotropic magnetization behavior of electrodeposited nanocrystalline Ni-Mo alloy thin films and nanowires array, J. Electrochem. Soc., vol. 159, pp. H800-H804, 2012.

[16] M. Wachtler, M. Winter, and J. O. Besenhard, “Anodic materials for rechargeable Li-batteries”, J. Power Sources, vol. 105, pp. 151-160, 2002.

[17] A. R. Kamali and D. J. Fray, "Tin-based materials as advanced anode materials for lithium ion batteries: a review”, Rev. Adv. Mater. Sci., vol. 27, pp. 14-24, 2011. 